\title{
Oficinas de prevenção em um serviço de saúde para adolescentes: espaço de reflexão e de conhecimento compartilhado
}

\author{
Workshops on prevention for adolescents \\ in a health service unit: a space for reflection \\ and shared knowledge
}

Leila Sollberger Jeolás 1

Rosângela A parecida Pimenta Ferrari 2

\footnotetext{
1 Departamento de

Ciências Sociais,

Universidade Estadual de Londrina.

Campus Universitário.

Caixa Postal 6.001, 86051-990, Londrina PR. claus@sercomtel.com.br

2 Departamento de Enfermagem,

Universidade Estadual de Londrina.
}

\begin{abstract}
This study analyzes the results and limits of a university extension project carried out in a public health service unit gi ving assi stance to adolescents. The project developed through the participative methodology, involved students and professionals from the fields of health and human sciences. It is justified by the increase in the indexes of non-planned pregnancy amongst young girls, in the indexes of infection by ST D and Aids, and drug use. The low number of programs turned to adolescents and the lack of a national project of sexual orientation in the schools increase the socialcultural vulnerability of young people. The workshops on prevention made it possible for a better interaction between professionals and adol escents, besides representing a space for reflection about sexuality-related subjects, hardly ever discussed within the family or at school. The workshops are presented, therefore, as effective tools in the prevention as well as in the promotion of health, and may be carried out in the health services by interdisciplinary teams.
\end{abstract}

Key words Adolescence, W orkshops on prevention, Vulnerability
Resumo 0 artigo analisa resultados elimites de um projeto de extensão uni versitária realizado em um serviço público de saúde com atendimento integral ao adolescente. 0 projeto foi desenvolvido através de metodologia participativa, envolveu acadêmicos e profissionais das áreas de saúde e humanas, respondendo à necessidade de se real izar trabal hos de preven ção com adolescentes. 0 projeto justifica-se pel o aumento dos índices de gravidez não planejada entre meninas; pelosíndices de infecção de DST e Aids; e pelo uso de drogas. Programas de saúde e o cumprimento dos conteúdos dos $\mathrm{Pa}$ râmetros Curriculares $\mathrm{N}$ acionais do M EC poderiam atuar para minimizar a vulnerabilidade sociocultural de jovens. O ficinas de prevenção possibilitaram melhor interação entre os profissionais do serviço e os adolescentes, além de representarem um espaço de reflexão sobre assuntos relacionados à sexualidade, temas dificilmente discutidos com a família ou na escola. As oficinas apresentam-se, portanto, como instrumentos eficazes de preven ção e de promoção à saúde, podendo ser operacionalizadas, nos servi ços de saú de, por equi pes interdisci plinares.

Palavras-chave Adolescência, O ficinas de preven ção, Vulnerabilidade 


\section{Introdução}

Estima-se, atualmente, de acordo com a Organização M undial de Saúde (OM S), que cerca de $50 \%$ das novas infecções pelo HIV no mundo estão ocorrendo na adolescência. Conforme o último Boletim Epidemiológico do M inistério da Saúde (2001), em torno de $70 \%$ dos casos de Aids ocorrem na faixa de 20 a 39 anos. Se considerarmos o período que o portador da enfermidade pode ficar assintomático - em média de 10 a 15 anos -, observase que a maioria dos casos de infecção de Aids deu-se da adolescência ao início da idade adulta. Além disso, vários estudos mostram que, apesar do elevado índice de conhecimento sobre as formas de transmissão, ainda são poucos os jovens que afirmam usar camisinha em todas as relações sexuais. Pesquisa sobre comportamento sexual da população brasileira (M inistério da Saúde, 1999) revela que, do total de indivíduos sexualmente ativos pesquisados, $76 \%$ não usam camisinha, sendo que os jovens de 16 a 25 anos são os mai ores usuários (44\%). Porém esse dado precisa ser relativizado, pois é justamente nessa faixa etária que a pesquisa constatou o mai or percentual de indivíduos com relações eventuais. Além disso, do conjunto daqueles que possuem uma relação estável e outra(s) eventual(is), 33\% não utilizam o preservativo na relação estável, mas apenas na eventual, sendo que $31 \%$ não o utilizam em nenhuma das duas relações sexuais. Outro importante fato revelado pela pesquisa, evidenciando a vulnerabilidade do jovem em relação às DST/Aids, é que $28 \%$ dos jovens sexual mente ati vos declararam fazer uso de álcool antes das relações sexuais, $18 \%$ deles habitualmente.

A vulnerabilidade do jovem vem sendo apontada também com relação à gravidez. A Pesquisa $N$ acional sobre D emografia e Saúde de 1996, comentada por Bruno e Bailey (1998), mostrou que, no Brasil, $18 \%$ das adolescentes de 15 a 19 anos já tiveram pelo menos um filho ou estão grávidas. Dados sobre partos realizados em hospitais ligados ao SU S, nos anos de 1994 e 1997, apontam para um aumento de gravidez entre jovens: em 1994 , do total de partos, $23,7 \%$ ( 2,85 milhões) foram feitos por meninas entre 10 e 19 anos; já em 1997, o número de partos nesta faixa etária aumentou para $26,5 \%$, embora o número total de partos real izados ten ha caído para 2,71 milhões (dados citados pela Folha de São
Paulo, 31/8/1998). Segundo Pesquisa $\mathrm{N}$ acional de Saúde Materno-Infantil da Bemfam de 1996 (citado por Camarano, 1998), a proporção de nascimentos não planejados foi de $59 \%$ entre as mulheres de 15 a 19 anos.

Em Londrina, de acordo com o Sistema de Informação de $\mathrm{N}$ ascimentos (D atasus-2002) da Secretaria M unicipal de Saúde, do total de 7.738 nascimentos, 1.478 (19,1\%) foram bebês de mães com menos de 19 anos de idade.

Tais dados, que justificam a necessidade de ações voltadas para 0 adolescente, motivaram a realização do projeto de extensão de oficinas de preven ção em um serviço de saúde de Londrina. Atendendo em média 850 adolescentes por mês, o projeto contou com a partici pação ativa de uma equipe multiprofissional.

Durante os dois anos de duração do projeto, foram realizadas 13 séries de quatro oficinas, de novembro de 1999 a dezembro de 2001, com a participação de 191 adolescentes, divididos em grupos com cerca de 12 adolescentes de ambos os sexos.

No segundo ano de realização do projeto, os questionários foram reformulados e incorporaram modificações propostas pela equipe no processo de avaliação. Para fins desta análise, foram tabulados os 93 questionários respondidos em 2001, representando uma amostra de 93 adolescentes. Destes, 53\% são do sexo masculino e $47 \%$ do sexo feminino, $96 \%$ dos meninos e $95 \%$ das meninas estudavam, enquanto $27 \%$ do sexo masculino e $23 \%$ do feminino trabal havam.

Além disso, é importante salientar que os adolescentes encaminhados para as oficinas são oriundos de entidades sociais ou das U nidades Básicas de Saúde, constituindo, portanto, população de baixa renda.

As oficinas tiveram a duração de três horas, perfazendo séries de doze horas, e abordaram os seguintes temas: "Sexual idade - 0 corpo que sente prazer"; "M étodos contraceptivos - o corpo que se reproduz"; "O corpo que adoece- DST"; "O ficina de sexo mais seguro - Aids". As oficinas foram implementadas segundo metodologia participativa utilizada por Villela (1996), baseada em técnicas lúdicas, vivências e dinâmicas de grupo. Tal metodologia possibilita trabalhar, simultaneamente, os aspectos cognitivos e afetivos da sexualidade, lidando, de modo articulado, com idéias, valores, práticas e comportamentos. 0 que define uma oficina é sua proposta 
de aprendizagem compartilhada, por meio de atividade grupal, face a face, com o objetivo de construir coletivamente o conhecimento. Os coordenadores apenas facilitam o debate, partindo sempre de dúvidas, opiniões e valores dos próprios participantes. Os exercícios e os temas trabalhados estimulam questionamentos, permitindo que se evidenciem os possíveis determinantes externos - classe social, gênero, idade - a imporem limites reais à autonomia pessoal. A partir das discussões, os adolescentes podem ampliar seus recursos de autoproteção.

O objetivo deste estudo é analisar os dados dos questionários aplicados aos adolescentes que participaram do projeto e suas respostas ao instrumento de avaliação das oficinas para trazer subsídios ao debate sobre a necessidade de se desenvolver projetos de prevenção e de promoção à saúde do adolescente, evi denciando os al cances e os limites da metodologia utilizada.

\section{Metodologia}

O presente estudo baseou-se na análise dos dois instrumentos de aval iação utilizados pelo projeto: um questionário com questões abertas e fechadas sobre conhecimentos, atitudes e práticas relacionados à sexualidade, saúde reprodutiva, DST e Aids, aplicado a cada grupo de adolescentes que participou dos blocos de quatro oficinas; e um roteiro de questões abertas sobre a opinião dos adolescentes acerca das técnicas utilizadas nas oficinas e o desempenho dos facilitadores.

0 questionário possibilitou a obtenção de dados relativos ao perfil dos adolescentes, aos conhecimentos, atitudes e práticas sobre sexualidade, contracepção, DST e Aids e aos vaIores acerca das relações de gênero. 0 questionário não objetivou avaliar aquisição de conhecimento ou mudança de comportamento a partir do trabalho das oficinas, pois a literatura tem demonstrado que avaliar conhecimento, atitudes e práticas em um prazo curto, como o da realização do bloco de quatro oficinas, é improdutivo e insuficiente (Giami, 1993; 1994). A mudança de comportamento é fruto de um processo complexo, ideológico, psíquico e afetivo que se realiza a médio e a longo prazo, demandando, portanto, uma continuidade de ações e projetos do próprio serviço de saúde, da escola e da comunidade, além de sofrer os efeitos das infor mações difundidas pelos meios de comunicação. As dificuldades para se al cançar metas de mudança de comportamento em saúde refletem a falta de investimentos na educação e na saúde, em nosso país, inviabilizando projetos e ações inter setoriais, contínuos, articulados à comunidade e sistematicamente avaliados.

A aplicação do questionário objetivou, portanto, buscar o perfil do adolescente que participa do serviço e produzir dados sobre o que ele pensa acerca das questões relacionadas à sexualidade para poder orientar o profissional do serviço no planejamento das próximas atividades e ações a serem implementadas e possibilitar comparações, ano a ano, ou comparações com dados oriundos da literatura nacional.

0 roteiro de questões abertas, aplicado ao final de cada oficina, objetivou avaliar como os adol escentes a vivenciaram, quais assuntos tiveram maior impacto sobre el es e quais comentários, dúvidas ou reflexões foram suscitadas. A interpretação de tais dados, oriundos da abordagem qualitativa, a partir da análise de conteúdo (Bardin, 1977), trouxe informações val iosas so bre a importância das oficinas para os adolescentes, mostrando que a avaliação de processo e o alcance de objetivos intermediários - para que se alcance metas al mejadas a médio prazo - são necessários e imprescindíveis, mesmo que não sejam, por si só, suficientes para a mudança de comportamento dos adolescentes em direção a práticas seguras rel acionadas à sexualidade.

\section{Resultados e discussão}

A análise dos dados do questionário e das respostas aos instrumentos de questões abertas para avaliar as oficinas demonstrou que 0 uso de metodologia participativa no projeto de extensão criou um espaço de discussão e de construção de conhecimento compartilhado entre os adolescentes, profissionais do serviço, professores e alunos.

O diálogo interdisciplinar entre profissionais e estudantes de enfermagem, medicina, serviço social e ciências sociais, em projetos de intervenção na área da saúde, tem permitido o exercício de desconstrução de categorias analíticas elaboradas no interior de cada ciência, como as de adolescência, de risco e de prevenção, quando as mesmas são recolocadas sob novas perspectivas, permitindo a 
compreen são sobre de qual adolescente se está falando, de que risco se trata equal tipo de prevenção é possível.

Sobre a apreensão de conhecimento para a ado ção de práticas sexuais segu ras, sabe-se de sua necessidade, mas, ao mesmo tempo, de sua insuficiência. Faz-senecessário igualmente trabal har com valores e sentimentos, sobretudo em relação a um assunto complexo como o da sexualidade. Além disso, a mudança de comportamento é processo prolongado, como já afirmado, edepende da ação de outros determinantes, como a família, a mídia e a escola. N este sentido, as oficinas representam o ponto inicial de um processo a ser complementado pela família, pela escola e por políticas sociais voltadas para os jovens em nosso país.

A partir da análise de conteúdo (Bardin, 1977; M inayo, 1993), pode-se depreen der das respostas dos adolescentes três categorias temáticas, organizadas a partir do conjunto das falas: espaço de reflexão; relações de gênero; conhecimentos e sentimentos.

\section{Espaço de reflexão}

Denominamos espaço de reflexão todo conteúdo referenteàs oficinas como espaço compartilhado de discussão. O sadolescentes enfatizaram a metodologia participativa das oficinaspropiciadora de auto-reflexão sobreos assuntos debatidos-, as dinâmicas utilizadas, a postura dos educadores-como ouvintes einterlocutores -, eo prazer de discutir, compartilhar eaprender.

Segundo os adolescentes, as oficinas propiciaram um lugar para falarem de assuntos dificilmente tratados em outros espaços institucionais, a não ser com seus pares. $N$ as palavras dos jovens, as oficinas representam um espaço para que eles comecem a refletir sobre as relações sociais nas quais estão inseridos, sobretudo no que diz respeito à sexualidade, podendo possibilitar a criação de uma maior autonomia, necessária paratorná-los sujeitos de sua própria sexualidade. Ali os adolescentes tiveram a oportunidade de discutir, em grupo, seusvalores, o quedificilmente fazem no cotidiano. D o conjunto das falas, algumas são exemplares:

cada dia que passa, as oficinas do CRAAL estão mais legais pois debatemos assuntos que não são discutidos na sociedade / falar sobrenós mesmos/ conhecer melhor os outros / senti confiança nos amigos/é muito bom ficar junto conversando sobre coisas que a gente não sabe / aprendi a me abrir com as pessoas e conversar sobre coisas que eu não dizia para ninguém.

Os dados obtidos na análise do questionário reforçam a afirmação dosjovens quanto à dificuldade dese abordar assuntos relacionadosàsexualidade. A figura 1 demonstra que $35 \%$ dos garotos e $29 \%$ das garotas conversam sobre sexo com amigos, $16 \%$ das garotas conversam também com a mãe ecom o professor e $14 \%$ dos ga-

\section{Figura 1}

Distribuição das respostas dos adolescentes sobre com quem conversam a respeito de assuntos relacionados à sexualidade

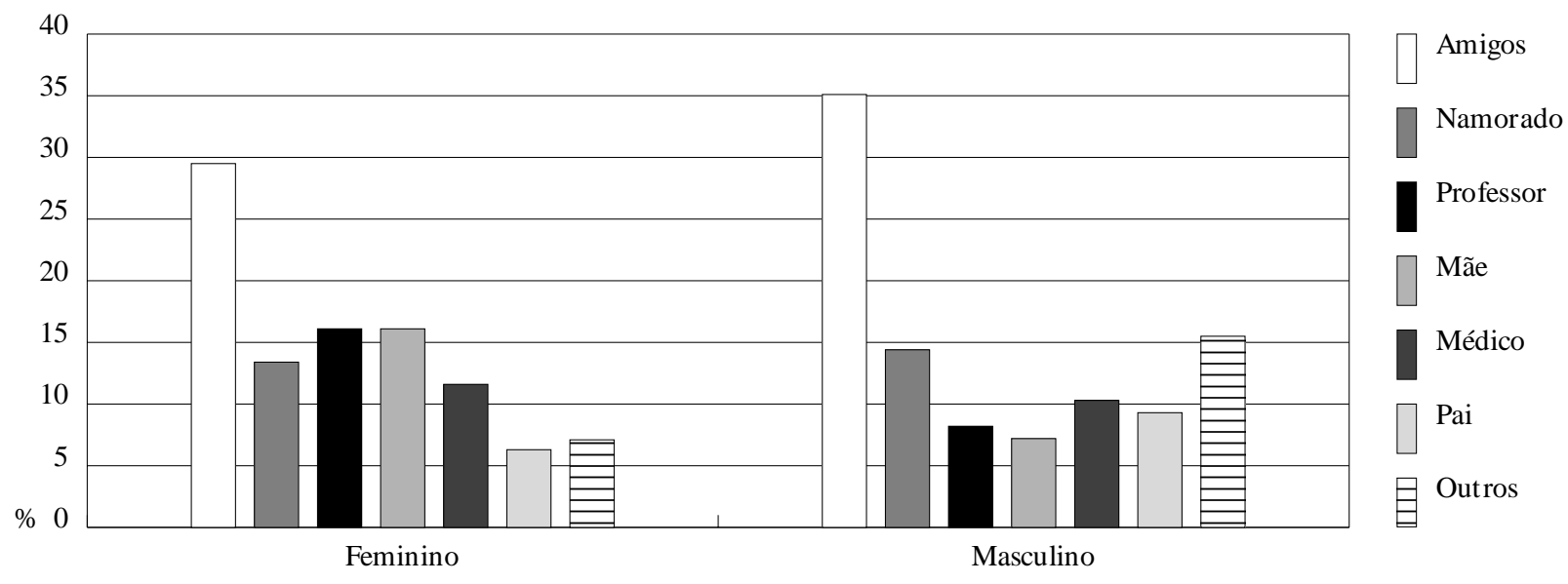


rotos conversam também com a namorada.

As dinâmicas de grupo tendem a permitir um debatemais aberto, bem exemplificado nas falas dos participantes:

não nos sentimos muito presos / uma forma diferente de discutir preven ção / senti prazer em aprender / ensinar com bom humor / uma mistura de educação e diversão / senti feliz em estar participando / deixaram que os participantes, nós, expressassem o que pensam / senti bem por estar falando sobre o que penso / gostei do teatro porque vocêsente na pele como é ter DST / gostei da atividade da argila; senti que tive uma liberdade para mostrar a parte do meu corpo que eu sinto mais prazer.

N esta perspectiva, como espaço para trocas de idéias evalores, as oficinas propiciam auto-reflexão sobrequestões sexuais, necessária à ruptura do indivíduo com a alienação produzida pelo mundo social, a qual perpassa sua condição individual. As oficinas representam um ponto inicial necessário, mas não suficiente, para busca da autonomia do sujeito frenteà sexualidade.

Rena (2001) afirma quea prática das oficinas consiste, justamente, na prática do ofício de pensar sobrea vidae senti-la a partir de cada componentee as histórias de todos que poderão ser reveladas e transformadas pela força dos argumentos e dos sentimentos compartilhados.

As oficinas de preven ção, como espaço dereflexão, pressupõem conceber o homem como sujeito ativo, um ser da práxis, da ação e da reflexão. Nesse sentido, M erchán-H amann (1999), analisando as contribuiç̧ões tanto de Freirequanto de Vygotsky, assinala o caráter ativo do sujeito no processo do conhecimento, quando o mesmo organiza tarefas de construção de significados a partir desuas próprias experiências.

\section{- Relações de gênero}

A análise da fala dos adolescentes permitiunos depreender a segunda categoria temática referenteàs relações de gênero.

D efinido como um conceito quenos permite melhor entender as representações do masculino e do feminino na prática social, o gênero tornouse uma categoria analítica de fundamental importância na interface das ciências da saúdee das ciências sociais. 0 conceito evidencia o processo de construção social, histórica ecultural das re presentações do masculino e do feminino na prática social. A forma hierarquizada das relações de gênero, em nossa sociedade, expressam diferenças significativas de como os adolescentes vivem epensam sua sexualidade.

Do total da população estudada, $53,7 \%$ relataram ter tido atividade sexual; desses, $70 \%$ eram garotos com média de idade da iniciação sexual de 14,5 anos, e $30 \%$ eram garotas e a média de idadeda iniciação sexual foi de 17,4 anos.

Os adolescentes apresentaram diferenças na forma como pensam evivenciam sua sexualidadeenos valores aela atribuídos, condizentes com as diferenças existentes na cultura sexual brasileira, que prioriza o papel ativo para o sexo masculino e o papel passivo para o sexo feminino (Parker eGalvão, 1996; Villela, 1996).

Em relação ao conhecimento eà exploração do próprio corpo, por exemplo, os adolescentes apresentam diferenças na forma como vivenciam a masturbação: $80 \%$ dos garotos relataram praticar, $18 \%$ relataram não praticar e $2 \%$ afirmaram não saber sobreo assunto. Das garotas, $25 \%$ relataram praticar a masturbação, $70 \%$ relataram não praticar e 5\% afirmaram não saber sobrea masturbação.

Em relação ao prazer sexual, a tabela 1 demonstra que, dentre os $53,7 \%$ dos adolescentes que tinham vida sexual ativa, $86 \%$ dos garotos afirmaram sempre sentir prazer nas relações sexuaise $14 \%$ às vezes. Quanto às garotas, $53 \%$ afirmaram sempre sentir prazer, $33 \%$ às vezes e $13 \%$ relataram nunca sentir prazer nas suas relações sexuais.

Quanto à virgindade, a tabela 2 demonstra quehá diferença na forma de os garotos e as garotas valorizarem sua importância. Em relação à pergunta "É necessário casar para fazer sexo?", $68 \%$ das garotas afirmaram sim e $20 \%$ não; enquanto entre os garotos, $53 \%$ responderam sim e $37 \%$ não. Em relação a se casar virgem, $45 \%$ das garotas disseram sim e $41 \%$ não; já entre os garotos, $12 \%$ responderam sim e $67 \%$ não. Ao serem questionados sobreo desejo de se casar com alguém virgem, $41 \%$ das garotas responderam

Tabela 1

Distribuição das respostas dos adolescentes que têm vida sexual ativa sobresentir prazer nas relações sexuais.

\begin{tabular}{lrrrr}
\hline \multirow{2}{*}{ Sente prazer } & \multicolumn{2}{c}{ Feminino } & \multicolumn{2}{c}{ Masculino } \\
& N & $\%$ & N & $\%$ \\
\hline Sempre & 8 & 53 & 30 & 86 \\
Às vezes & 5 & 33 & 5 & 14 \\
Nunca & 2 & 13 & 0 & 0 \\
Total & $\mathbf{1 5}$ & $\mathbf{1 0 0}$ & $\mathbf{3 5}$ & $\mathbf{1 0 0}$ \\
\hline
\end{tabular}


Tabela 2

Distribuição das respostas dos adolescentes quanto à opinião sobrevalores referentes à sexualidade

\begin{tabular}{|c|c|c|c|c|c|c|c|c|c|c|c|c|}
\hline \multirow[t]{3}{*}{ Respostas } & \multicolumn{4}{|c|}{ Precisa casar para fazer sexo? } & \multicolumn{4}{|c|}{ Você quer casar virgem? } & \multicolumn{4}{|c|}{ Quer casar com alguém virgem? } \\
\hline & \multicolumn{2}{|c|}{ Feminino } & \multicolumn{2}{|c|}{ Masculino } & \multicolumn{2}{|c|}{ Feminino } & \multicolumn{2}{|c|}{ Masculino } & \multicolumn{2}{|c|}{ Feminino } & \multicolumn{2}{|c|}{ Masculino } \\
\hline & $\mathrm{N}$ & $\%$ & $\mathrm{~N}$ & $\%$ & $\mathrm{~N}$ & $\%$ & $\mathrm{~N}$ & $\%$ & $\mathrm{~N}$ & $\%$ & $\mathrm{~N}$ & $\%$ \\
\hline Sim & 30 & 68 & 26 & 53 & 20 & 45 & 6 & 12 & 10 & 23 & 29 & 59 \\
\hline Não & 9 & 20 & 18 & 37 & 18 & 41 & 33 & 67 & 18 & 41 & 4 & 8 \\
\hline N ão sabe & 5 & 11 & 5 & 10 & 6 & 14 & 7 & 14 & 16 & 36 & 15 & 31 \\
\hline NR & 0 & 0 & 0 & 0 & 0 & 0 & 3 & 6 & 0 & 0 & 1 & 2 \\
\hline Total & 44 & 100 & 49 & 100 & 44 & 100 & 49 & 100 & 44 & 100 & 49 & 100 \\
\hline
\end{tabular}

não, 36\% não sabiam e $23 \%$ responderam sim; no grupo dos garotos, $8 \%$ deles responderam não, $31 \%$ responderam que não sabiam e $59 \%$ responderam sim.

Os dados da tabela 2 reforçam as falas dos adolescentes durante as discussões em grupo e nas respostas ao instrumento de questões abertas para avaliar as oficinas. Os adolescentes manifestaram a possibilidade do desvendamento de alguns aspectos inerentes às relações de gênero em nossa sociedade, quando pareceram descobrir a condição feminina e masculina e, conseqüentemente, seu papel na relação homem/muIher. Seguem algumas das fal as significativas neste sentido:

aprendi a valorizar mais as mulheres eaprendi as suas dificuldades, são importantes para vida do homem / saber as opiniões das mulheres de como ser menos machista / aprendi muitas coisas que não sabia, por exemplo como fazer uma muIher atingir 0 orgasmo / senti que há muitas diferenças, mas que nem por isso os homens são tão diferentes das mulheres / conhecer mel hor os sentimentos das mulheres, como elas pensam e como querem quenós pensamos / senti quehá mais preconceito da mulher que do homem / qualidades desiguais e direitos do sexo oposto / aprendi que como sempre o homem é muito ignorantee preconceituoso como sempre foi / senti que para os homens o que importa é ser o gostosão e para eles um pênis grande impõe respeito.

0 conceito de gênero refere-seà imbricação de co-determinações existentes entre o biológico eo social. A história da sexualidade no 0 cidente tem sido caracterizada como fenômeno individual ebiológico e objeto de estudo, sobretudo, dasciências médicas, como problema clínico ede saúde. Justamente contra essa concepção de sexualidade, o conceito de gênero possibilita tratar dos valores, das imagens e das representações, para além do biológico, presentes nas relações humanas. Segundo Giffin (1995): nesta concepção não dualista, a dimensão biológica não é determinante, nem é desconsiderada, pois o fenômeno da sexualidade é enfocado como uma interface que relaciona, dialeticamente, o biológico eo social (...).

\section{- Conhecimentos e sentimentos}

A última categoria temática depreendida das fal as dos adolescentes refere-se aos conhecimentosadquiridose sentimentos experimentadosdurante sua partici pação nas oficinas. O sadolescentes demonstraram conhecimento básico sobre formas de transmissão e de prevenção das DST e Aids e sobre métodos contraceptivos. Quanto ao método contraceptivo indicado para adolescentes, $32 \%$ dos garotos e $31 \%$ das garotas citaram a camisinha masculina, 37\% dos garotos e $24 \%$ das garotas citaram a camisinha feminina, e $35 \%$ dos garotos e $25 \%$ das garotas, as pílulase injeções. AsDST conhecidas mais citadas foram gonorréia, sífilis eAids. Quanto à forma deseevitar DST eAids, $86 \%$ das garotas e $73 \%$ dos garotos referiram-seà camisinha.

Entretanto as respostas quanto ao uso do preservativo nas relações sexuais demonstram que o adolescente está vulnerável à gravidez eà infecção deDST eAids. Do total dos $53,7 \%$ adolescentes quetinham vida sexual ativa, $44,7 \%$ dos garotos e $14,9 \%$ das garotas relataram usar camisinha sempre nas relações sexuais; $16,7 \%$ dos garotos e $13 \%$ das garotas relataram às vezes usar camisinha nas relações sexuais; e 3,7\% dos garotos relataram nunca ter usado a camisinha nas relações sexuais.

Pesquisas deabordagem qualitativaapontam para a relatividade do uso da camisinha reportada pelos jovens, uma vez que o seu uso éabando- 
nado quando se conhece o parceiro, se tem um só parceiro, seconfia no parceiro, dentre outros motivoscitados (Paiva, 1994; Jeolás, 1998).

Estudos sobre prevenção com adolescentes apontam para os baixos índices de adoção de práticas sexuais seguras, apesar dos índices ele vados de conhecimento (M inistério da Saúde, 1999). Cerqueira Leite $(1994 ; 1995)$ demonstrou, em seus dois estudos sobre jovens universitários, queégrandea porcentagem daqueles que percebem o risco daAids para os jovens, de modo ge ral, enquanto a porcentagem dos que percebem 0 seu próprio risco individual éinversamentepequena.

0 mesmo foi encontrado no projeto de extensão aqui analisado. A figura 2 demonstra que, do total dos adolescentes, $86,4 \%$ das garotas e $85,7 \%$ dos garotos consideraram que o risco deo jovem adquirir Aids hoje em dia é grande, enquanto a figura 3 demonstra que, do total deadolescentes, $11,4 \%$ das garotas e $10,2 \%$ dos garotos consideraram ser grandeseu próprio risco deadquirir Aidshojeem dia.

A aquisição de conhecimento sobre sexualidade, métodos contraceptivos, DST eAids foi enfatizada pel os adolescentes, em quase todas as respostas, como avaliação positiva das oficinas.

Quando o conhecimento adquirido referiase a métodos, reprodução humana, aparelho reprodutor feminino emasculino, DST eAids, os adolescentes se expressaram de maneira sintética ecom pouca manifestação de sentimentos: conhecer melhor o corpo / aprender sobre o corpo e aparelhos genitais / aprendi mais sobre meu corpo e dos homens também / partes externas de ambos os sexos / aprendi sobre DST eAids, aprendi muitas coisasque não sabia.

Quando o conteúdo do conhecimento referia-se à sexualidade, ao corpo, ao prazer, ao orgasmo e às diferenças homem/mulher, muitas vezes vinha acompanhado de expressão de sentimentos relacionados a esses assuntos. Das várias falas, citamos al gumas:

parte do corpo que senti mais tesão, senti um friozinho na barriga / no nosso corpo tem muitos lugares que sentimos tesão / sobre sexo oral e anal, énojento / muito legal porquevocês não têm medo de falar a verdade na sexualidade / aprendi que 0 assunto sexo é diferente até mesmo pela idade, pessoas mais vel has que têm vida sexual ativa pensam totalmente diferente / senti como se alguém estivesse tocando minha nuca / como fazer sexo com prazer ea realidade dos meninos.

Ao lado do conhecimento adquirido, muitas vezes os adolescentes referiram-sea sentimentos de vergonha e de incômodo, os quais, segundo eles, desapareceram, no decorrer dos diferentes exercícios e dinâmicas compartilhados:

senti quea gente deve demonstrar do que gosta do corpo, apesar da vergonha / se expressar sem vergonha / conhecer mel hor o físico eas partes que tenho vergonha de mencionar / massa, porquetenho vergonha de demonstrar onde tenho prazer $e$ receio / quenão preciso ter vergonha do meu cor-

Figura 2

Distribuição das respostas dos adolescentes sobre o risco de o jovem pegar Aids

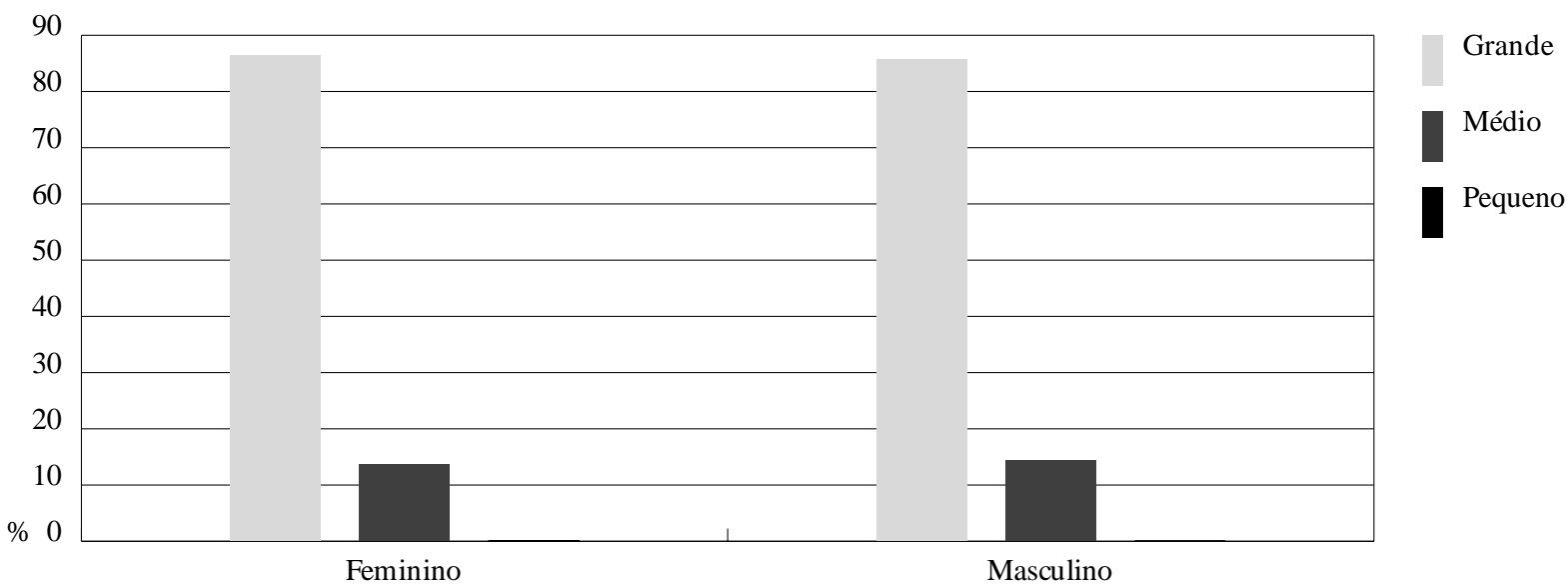


Figura 3

Distribuição das respostas dos adolescentes sobre o próprio risco de pegar Aids

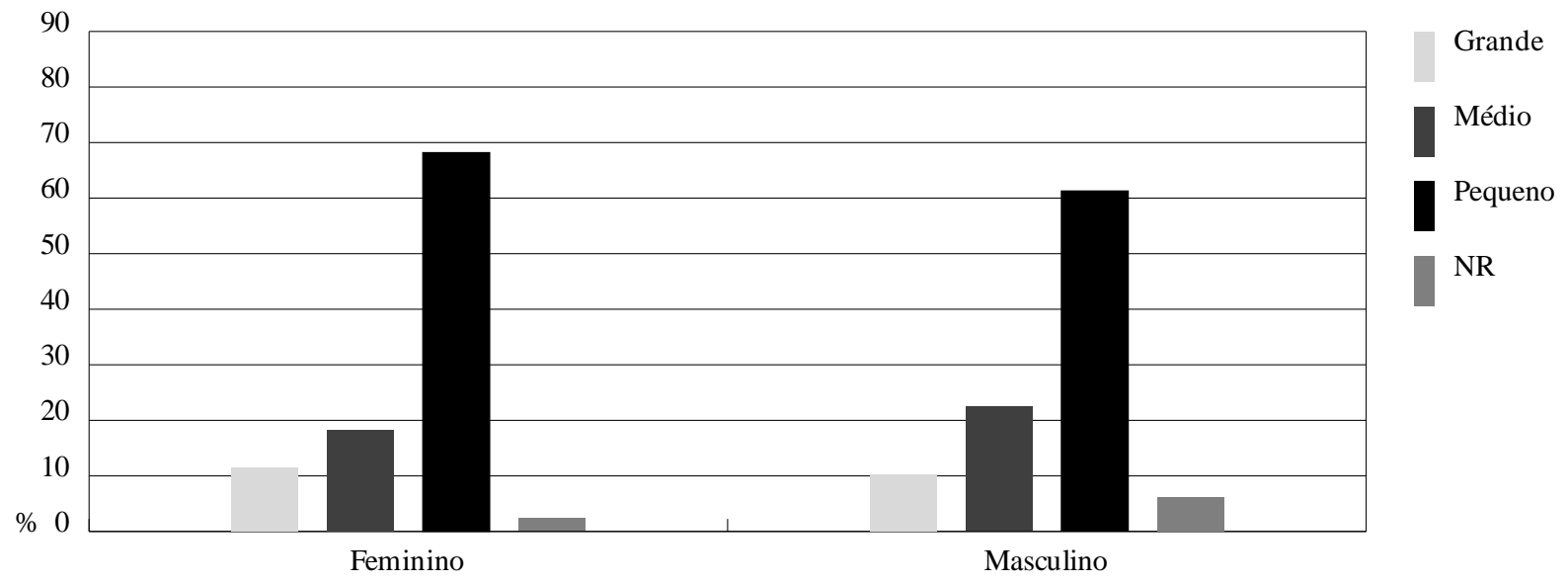

po / mais debate, mais aprofundamento naqueles assuntosmaisindiscretos.

A vergonha ou o constrangimento de falar sobresexo está relacionado ao tabu da sexualidade eà dificuldade de abordar o tema. Segundo Rena (2001), há que se considerar as intrincadas relações subjacentes ao discurso sobre sexo/ sexualidade e todos os sentimentos que esta prática discursiva podemobilizar em nossa sociedade. Isso refleteo processo de regulação da sexualidade nas sociedades ocidentais, largamente analisado por Foucault (1984).

Se os conhecimentos apreendidos são necessários, mas insuficientes para adoção de práticas seguras, como já dito anteriormente, há evidências nas falas analisadas de queas oficinas podem desencadear processos internos de revisão de valores e condutas, a exemplo desta fala sobregênero: aprendi a valorizar mais as mulheres eaprendi as suas dificuldades, são importantes para a vida do homem, que aponta uma tendência de abertura para revisão dos papéis sexuais estabelecidos. É possível também identificar algumas ten dências de mudança de atitude em relação ao usuário de drogas, ao portador do vírus daAidse às pessoas com DST, como expressam alguns adolescentes:

[sobre a dramatização] sentir o sentimento das pessoas infectadas/ não excluir um ex-drogado, senão el e volta a se drogar / que não se pode discriminar um aidético, porque num vacilo você pega.

\section{Considerações finais}

A avaliação de meta dos trabal hos de prevenção degravidez, DST e Aids, voltados para adolescentes, tende a ser negativa, se o esperado for a mudança de comportamento, expressa, sobretudo, no uso do preservativo. A curto ea médio prazo, essa mudança parece pouco provável, se considerarmos a bibliografia sobreo assunto. A meta última - mudança de comportamento, sobretudo o uso do preservativo -, como bem demonstram as pesquisas, não tem sido alcançada. Os índices relativos a novas infecções não demonstram sinais de diminuição. No Brasil, as taxas sobre uso de preservativo são muito baixas. Segundo a última pesquisa do M inistério da Saúde (1999), já citada, apenas cerca de 27\% da população sexual mente ativa reporta usar 0 preservativo nas suas relações sexuais.

N essa perspectiva, a avaliação de meta deverá ser, portanto, adiada ea aval iação de processo deve ser implementada com objetivos intermediários bem definidos, fundamentais para redução da vulnerabilidade dos adolescentes. Citamos alguns: desconstruir metáforas negativas relacionadas à Aids; propiciar espaço para discussão e reflexão sobre sexualidade, desfazendo medos e tabus e, assim, colaborar para que os jovens se tornem sujeitos de sua própria sexualidade; criar espaços para que os jovens possam refletir sobre a relatividade ou a hierarquia dos riscos vividos atualmente por eles, partindo de 
suas próprias experiências e das dificuldades de optarem por práticas de proteção. N esse processo, o papel dos profissionais não poderá ser o de transmissor vertical de conhecimento, nem tampouco o de transmissor de valores pessoais relativos à sexualidade, empreendendo um exercício disciplinar queassegura uma determinada manutenção do status quo sexual e da sacralidade da ordem social estabelecida. 0 papel dos profissionais deverá ser o de interlocutores, de facilitadores da discussão e da reflexão.

Tendo em vista essas considerações, Chauí (1991) al erta para o fato de quea educação sexual pode ter também objetivos li mitados e repressivos, e que a implantação de um programa por si só não garante que se esteja visando a metas mais amplas, como a realização de ser humano, a emancipação da mulher, a igualdade entre sexos e a aceitação do prazer na vida sexual.

0 processo de educação sexual deve ser exercido não como domesticação dos indivíduos, mas como uma oportunidade de autoreflexão, a partir da qual o indivíduo possa se estabelecer como sujeito e exercer uma visão crítica e uma práxis transformadora sobre sua sexualidade, o que contribuiria para a afirmação dos ideais emanci patórios da humanidade, a partir do respeito ao outro eàs diferentes formas de exercício da sexual idade.

D entre as maiores dificuldades encontra- das, destacamos a falta de continuidade das ações de prevenção desenvolvidas pelo serviço de saúde, a partir deum projeto de prevenção. As ações deveriam ser contínuas e articuladas interinstitucionalmente, por exemplo, capacitando os profissionais das entidades sociais (escolas, entidades e programas sociais) que encaminham os adolescentes para as oficinas no serviço de saúde, com o intuito de formar multiplicadores em seus locais de trabalho, para que el es dêem prosseguimento às ações de prevenção, baseadas em metodologia participativa, em suas próprias instituições de origem (Ayres, 1999). Dessa forma, os adolescentes seriam acompanhados e poderiam receber também formação para atuarem como multiplicadores junto a seus pares.

0 efeito do trabalho de prevenção realizado com metodologia participativa para os adolescentes que freqüentaram as oficinas é de difícil mensuração, mas apostamos no pressuposto de que o objetivo desses trabaIhos deve ir além das preocupações higienistas e epidemiológicas. A fala de um dos adolescentes é exemplar sobre a potencialidade das oficinas como espaço decompartilhamento de saberes:

Novo para mim. É um trabalho de resultados um pouco demorado, mas para que haja uma soci edade culta e informada, é este tipo de iniciativa que está faltando.

\section{Agradecimentos}

O projeto de extensão universitária "Oficinas de prevenção: gravidez, DST e Aids" foi realizado no Centro de Referência e Atendimento ao Adolescente de Londrina (CRAAL), contando com a participação e o envolvimento sistemático da equipe de profissionais: $M$ aria Lúcia G. Guerchmann, Walter M arcondes Filho, Regina Lúcia César de Oliveira, M arlei Storti, M aurílio J. M aina, A parecida T. Kuriaki, Lorelai K. Araújo, Cesar Kohatsu; dos acadêmicos de Ciências Sociais ( 20 ano): Tiago dos Santos, Carolina Ferreira, Elias Barreiros, Daniel M edeiros, Elizeu Carvalho, Sonia Cristina da Silva; dos acadêmicos de Enfermagem ( 30 ano): Cristiane Regina M. Zanini, Eliene Paula dos Santos, Tatiana H arumi M issugui e Lilian Daiane Palma; e do acadêmico de M edicina ( 2 o ano): Bruno Ferreira. Sem a colaboração de todos, não só na realização das oficinas, mas também no processo de avaliação da metodologia e dos resultados, o projeto não teria sido possível. 


\section{Referências bibliográficas}

Ayres JR et al. 1999. Vulnerabilidade e prevenção em tempos de Aids. In RM Barbosa \& R Parker (orgs.). Sexualidades pelo avesso. Direitos, identidades e poder. IM S-UERJ-Ed. 34, Rio de Janeiro-São Paulo.

Bardin L 1977. L'analyse de contenu. Press U niversitaires de France, Paris.

Bemfam 1992. Pesquisa sobre saúde reprodutiva e sexualidade do jovem: Rio de Janeiro, Curitiba e Recife- 1989/90. Rio deJaneiro.

Bruno ZV \& Bailey PE 1998. Gravidez em adolescentes no Ceará: maternidade ou aborto? Seminário Gravidez na Adolescência. M inistério da Saúde, Projeto de Estudos da M ulher/Family H ealth International, Associação Saúde da M ulher, USAID.

Camarano A 1998. Fecundidade e anticoncepção da população de 15 a 19 anos. Seminário Gravidez na Adolescência. M inistério da Saúde, Projeto de Estudos da M ulher/Family H ealth International, Associação Saúde da M ulher, USAID.

Cerqueira Leite RM 1995. Psychosexual characteristics of male university students in Brazil. Adolescence30(118) summer.

Cerqueira Leite RM 1994. Psychosexual characteristics of female university students in Brazil. Adolescence 29 (114) summer.

Chauí M 1991. Educação sexual: instrumento de democratização ou de mais repressão? Cadernos de Pesquisa 36(fev.).

Datasus. <www.datasus.gov.gr >. Acessado em 5 de agosto de 2002. SINASC-2000.

Foucault M 1984. H istória da sexualidade 2: 0 uso dos prazeres. (7a ed.). Graal, Rio de Janeiro.

Giami A 1994. De Kinsey à Aids: a evolução da construção do comportamento sexual em pesquisas quantitativas. In M A Loyola (org.). Aids e sexualidade: 0 ponto de vista das ciências humanas. Relume Dumará-U erj, Rio de Janeiro.

Giami A 1993. Connaissances, attitudes, croyances, comportements: les limites du paradigme KABP.
Transcriptase, Revue Critique de l'Actualité Scientifique Internationale sur le Sida 17 , juillet-août, Paris.

Giffin K 1995. Gênero e saúde. Curso ministrado no I Congresso Brasileiro de Ciências Sociais e Saúde. Abrasco-NESCO-PR, Curitiba.

J eolás LS 1999. 0 jovem e o imaginário da Aids. 0 bricoleur de suas práticas e representações. Tese de doutorado, PUC-SP.

Merchán-H amann E 1999. Os ensinos da educação para a saúde na prevenção de HIV-Aids: subsídios teóricos para a construção de uma práxis integral. Cadernos de Saúde Pública 15(2).

M inayo M C 1993. 0 desafio do conhecimento. Pesquisa qualitativa em saúde. Hucitec-Abrasco, São PauloRio de Janeiro.

M inistério da Educação e Cultura 1997. Parâmetros Curriculares $\mathrm{N}$ acionais: introdução aos Parâmetros Curriculares $\mathrm{N}$ acionais. Secretaria de Educação Fundamental. MEC/SSEF, Brasília.

Ministério da Saúde - PN DST/AIDS 1999. Projeto Comportamento Sexual da População Brasileira e Percepção sobre HIV eAids. Brasília.

M inistério da Saúde 2001. Boletim Epidemiológico/Aids fevereiro-março.

Paiva V 1994. Sexualidade e gênero num trabalho com adolescentes para prevenção do HIV/AIDS. In R Parker et al. (orgs.). A AID S no Brasil (1982-1992). Relume-Dumará-ABIA-IM S-UERJ, Rio de Janeiro. (História Social da Aids, 2).

Parker R \& Galvão J (orgs.) 1996. Q uebrando o silêncio: mulheres e Aids no Brasil. Relume Dumará-ABIAIM S-UERJ, Rio de Janeiro. (H istória Social da Aids, 7).

Rena LCCB 2001. Sexualidade e adolescência. As oficinas como prática pedagógica. Autêntica, Belo Horizonte. (Coleção Trajetória).

VillelaW 1996. Oficinas de sexo mais seguro para mulheres. A bordagens metodológicas e de avaliação. NEPAIDS-USP, São Paulo.

Artigo apresentado em 20/9/2002

A provado em 22/10/2002

Versão final em 20/11/2002 